\title{
Development of Tea Culture Tourism Resources in Xinjiang under the Background of "Belt and Road"
}

\author{
Hongxia Wu \\ Southwest University for Nationalities, Southwest Minzu University, Chengdu, 610041, China
}

Keywords: The "Belt and Road", Xinjiang, tea culture tourism, development.

\begin{abstract}
Tea occupies an important position among all ethnic groups in China and is an indispensable condiment in people's daily life. In Xinjiang, where multi-ethnicity is concentrated, tea also plays a connecting role in people's life exchanges. Based on the construction of "Belt and Road" as the background, this paper explores the rich and diverse characteristics of Xinjiang's tea culture, and conducts research on its tourism development to introduce Xinjiang's tea culture to the outside world, promoting the development of Xinjiang's tea industry while better promoting Chinese tea culture.
\end{abstract}

\section{Introduction}

The "Belt and Road" proposed by President Xi Jinping is not only a road to trade, but also a road to culture, a road to tourism, and a road to peaceful development. Under this great initiative, Xinjiang has become a key area of the "Belt and Road" and its diverse tea culture can promote tourism development in Xinjiang. In other parts of the country, tea gardens, tea art, tea ceremonies, tea dances and many other tourism modes have been launched and are popular among tourists. Although Xinjiang is not China's tea production area, it is an important tea consumption area in China. There is a long history of tea in Xinjiang. The different tea cultures formed from the understanding and tea drinking of various ethnic groups in Xinjiang are also the beautiful scenery in the construction of the "Belt and Road", which is worthy of research on tourism development.

\section{Tracing the Origin of Xinjiang Tea Culture}

China is the hometown of tea, with thousands of years of tea production and tea drinking history. Tea appeared in the Shang and Zhou Dynasties. During the Tang and Song Dynasties, tea entered thousands of households. As a carrier of culture, tea gradually formed a tea culture with Chinese characteristics in its circulation. The Tea Classic by Lu Yu is very rich in content, including the origin and history of tea, tea planting, tea production, tea boiling, tea drinking, tea sets and other aspects of tea. ${ }^{[1]}$ Tea has the functions of making the body healthy, as well as healing and self-cultivation. Tea is closely related to people's life, ranging from the taste of tea drinking by the nobles and literati to the custom of tea drinking for ordinary people. Besides, people's love for tea is also reflected in poems, songs, couplets, proverbs, songs, dances and other aspects, such as One-word to Seven-word Poem Tea by the Tang poet Yuan Zhen, West River Moon - Tea Words by the Song poet Su Shi, and Happy For the Spring - For the Teahouse by the Yuan songwriter Li Dezai, which shows that tea has been integrated into people's spiritual life.

Tea is a necessity for people of all ethnic groups in Xinjiang and is very popular among local people. Unlike Han people who drink tea, there are more meat products and dairy products in ethnic minority diets, which are not only difficult to digest, but also lack trace elements needed for life and are prone to illness. Tea contains vitamins $\mathrm{A}$ and $\mathrm{E}$ and trace elements such as calcium, magnesium and sodium. It also removes cellulite and grease and clears heat and toxicity, diuretic and good for teeth, refreshing, strengthening heart and resisting cancer, reducing blood fat, resisting radiation, good for eye and cleaning skin, etc. [2] Tea can both supplement the nutrients needed by the body and 
help digestion for people's health. Therefore, tea has become necessary for the life of ethnic minorities, affecting people's production, life and customs.

Xinjiang has been an important area of the ancient Silk Road, and tea has also come along the Silk Road and has gradually become a special local cultural phenomenon. Some local teas are also produced in Xinjiang, mainly including the "Western Magical Grass" grown in Lop Nor and Lop Village area, Apocynum venetum tea, Tianshan snow chrysanthemum and Chamomile tea, as well as Willow tea, Bark Jade rose tea, Ili Sour straw tea and South Xinjiang eucalyptus tea in Ili and Usu. According to Tang Libiao, some self-produced teas in Xinjiang are actually processed wild plant leaves used as substitutes by local people when the tea is in short supply. [3] In different dynasties, the demand for tea in Xinjiang was valued by the rulers. During the reign of Emperor Qianlong, the source of Xinjiang tea was mainly due to the large amount of tea from the Qing government in the form of "official tea".

Since the founding of the People's Republic of China, China has attached great importance to the demand for tea consumption by the Xinjiang people, and has provided the tea needed for the people's life in Xinjiang at different times. For example, in November 1949, the Ministry of Trade of the Northwest Military and Political Committee dispatched 30,000 packages of brick tea (60t) to Xinjiang. China was in a period of economic hardship in 1960. However, the policy of guaranteeing supply in Xinjiang was still adopted, and 8650t was transferred. 200t of red, green and flower teas were increased, as well as red and green brick tea besides the planed transfer. [4] The large demand for tea in Xinjiang has also stimulated the emergence and formation of tea merchants and tea markets. The formation of the tea market in Urumqi has its historical process. In the 1990s, some tea merchants appeared in Xinjiang. Around 2002, dozens of tea shops were concentrated in Luyuan Street, marking the basic formation of Urumqi tea market. Subsequently, in order to meet the market demand, the tea dealers represented and sold well-known teas, and opened the branches in the Hualing market of the capital, and the Xinjiang tea market gradually grew.

For now, the living standards of people in Xinjiang have been significantly improved. The transportation, network and logistics are all developed. The teas needed for people's lives include not only green tea, white tea, yellow tea, green tea and black tea from the motherland, but also tea imported from countries such as Turkey and Sri Lanka. According to the statistics of Xinjiang Tea Culture Association, there are currently more than 1,500 tea dealerships in Xinjiang. The scale of Xinjiang tea market ranks in the top ten in the country. The annual sales volume of tea (excluding flower tea) is between 2,000 tons and 3,000 tons, and the sales amount is about 1 billion yuan. [5] These are not only an objective description of the Xinjiang tea market, but also a concrete manifestation of Xinjiang tea culture. Urumqi, the capital of Xinjiang, known as the "Asian Capital", is not only the bridge connecting the East and the West on the Silk Road, but also the core place for the wholesale, retail and distribution of tea in Xinjiang under the "Belt and Road" construction, or the northern and southern parts of Xinjiang. The source of tea purchases is even the tea importing places in Central Asian countries such as Kazakhstan. The different tea cultures of different ethnic groups in Xinjiang constitute the Xinjiang tea culture, enriching the tea culture in China, and developing the multi-ethnic tea culture in Xinjiang under the "Belt and Road" initiative, thereby promoting the healthy development of the Xinjiang tea industry and providing tourism to Xinjiang. A new economic growth point will play a role in promoting the spread of tea culture on the Silk Road.

\section{Characteristics of Xinjiang Tea Culture}

People living in Xinjiang like to eat beef and mutton and their by-products. These foods are greasy, hot and not digestible, while teas containing vitamins and theophylline not only solve the dietary problems of local people, but also have the effect of refreshing and quenching thirst. Xinjiang, a country with many ethnic minorities, is accustomed to be called Northern Xinjiang and Southern Xinjiang. People in northern Xinjiang like to drink milk tea. People in southern Xinjiang like to drink "medicine tea". No matter in restaurants in the market or at home, people cannot eat without tea. Tea is used as a daily necessity for people of all ethnic groups in Xinjiang. In the social development, 
Xinjiang, a multi-ethnic settlement, has formed a rich and unique tea culture.

\subsection{Rich tea types}

The tea on the ancient Silk Road not only melts into the lives of the people of Xinjiang, but also produces a diverse tea culture. Xinjiang has a wide variety of teas and a wide range of sources, including six tea types from outside Xinjiang, as well as apocynum tea, Kunlun snow chrysanthemum, willow tea [6], sour straw tea, eucalyptus tea, rose tea from Hetian, and lavender tea and chamomile tea from Ili. In addition, there are many kinds of fragrant tea, milk tea and sweet tea prepared by local people in Xinjiang. Under normal circumstances, people in northern Xinjiang like to drink milk tea with milk, salt and milk skin; people in southern Xinjiang like to drink fragrant tea with cardamom, cloves, cumin and other powders. The Mongolian, Kirgiz, Kazakh, Uzbek and other ethnic groups in Xinjiang like to drink milk tea, but their specific methods of brewing have similarities and their own characteristics, which reflect the wisdom of local tea drinking.

\subsection{Distinctive tea sets}

Drinking tea is inseparable from tea sets. In addition to a wide variety of teas, there are many tea-related derivatives in Xinjiang. Tea sets are an intuitive embodiment of Xinjiang tea culture. For example, Abu Dhawa [7] used by the Uyghurs for clean hands, Samaval [8] for boiling water, Tinus [9] for tea, and Piale [10] for tea. In addition, there are ceramic pots, saucers, teaspoons, large tea bowls and other tea sets. The tea sets used by Kazakhs mainly include enamel teapots, Jingdezhen's glass tea sets with ceramic tea bowls and small teapots for drinking green tea. Mongolians use ceramic bowls, porcelain pots or copper pots, iron pots, etc.

\subsection{Diverse tea drinking places}

Xinjiang people should drink tea when they are eating at home. When they are drinking, they should drink tea and drink tea when they are married. Tea has penetrated into every aspect of people's lives. Xinjiang's teahouses, tea bars, teahouses, teahouses, teahouses, teahouses, and tea gardens are everywhere. For example, there are hundreds of tea drinking places in Urumqi, Kashgar, Hetian, and Yili. There are also many tea drinking places, and some tea houses already exist. For hundreds of years, it has a long history. Tea drinking places are not only the place where people drink tea, but also the public space where people chat, relax and strengthen interpersonal relationships. For example, in a century-old teahouse in the old town of Kashgar, people can order pots of tea in the teahouse, buy a pot, and meet the needs of diet and rest with very little money. Tears sometimes dance the piano in the teahouse, and the teahouse becomes a cheerful entertainment venue. Some tea drinkers will also talk about some new things happening in the society in the teahouse; the teahouse is also the place where people talk about business. The teahouse provides people with space for singing and dancing, anecdotes, and information exchange. People can talk about tea in them. Enjoy tea fun.

\subsection{Diverse tea customs}

The tea culture customs in Xinjiang have multiple characteristics. Under normal circumstances, Kazakhs prefer to use "please drink a pot of tea" when inviting friends to eat, because "I invite you to eat a meal" is not only cheesy in Kazakh, but also implies the meaning of sympathy and charity. Since cooking a pot of tea for about 15 minutes, the boiled tea is used by the Kazakhs, and the breakfast time is called "tea time." In the eyes of the Kazakhs, the order of cooking tea and its techniques, the water for cooking tea, is also very particular. They think that the best water in the tea, the spring water and the stream, and finally the river. The owner of the Uyghur teahouse likes to use apricot wood, mahogany and other firewood to burn tea, because these fruit trees have aroma and can make tea more fragrant than that with gas or electricity. Besides, some ginger, cinnamon and pepper are added. Tea plays an important role in Uyghur banquets, eating, circumcision, kinship and other ceremonial activities. In addition, people also carry out some tea-related games and activities, such as tea games in Mexilip; The Samavar dance with tea trays and performances; the bowl dance of Uighur women's performances, all related to tea culture customs. 


\section{Development Countermeasures of Xinjiang Tea Culture under the Background of the Belt and Road Initiative}

Throughout the ages, tea is an important trade item on the Silk Road. Tea-horse trade is both a witness and a manifestation of trade prosperity. Nowadays, under the construction of the "Belt and Road", the positive role of tea culture as a Chinese civilization to the world has not changed. Xinjiang, an important gathering place for the economic and cultural aspects of the East and the West, should continue to develop and promote Xinjiang tea culture from various aspects, highlight the characteristics of Xinjiang Tea City, and provide new innovative points for tourism culture in Xinjiang, to attract tourists to travel to Xinjiang and understand the tea culture in Xinjiang. For the development of Xinjiang tea culture, we can start from the following aspects:

\subsection{Development of Xinjiang Multi-ethnic Tea Customs and Tea Manners}

There are 47 ethnic groups in Xinjiang and 13 inhabitants of the world. Different ethnic groups have different tea cultures. Developers can cooperate with local minority residents to establish minority tea drinking houses. When tourists come to Xinjiang, they can combine the tourist areas where tourists are located to show local tea customs, so that visitors can learn about different local tea customs and tea manners. Xinjiang multi-ethnic tea culture is also reflected in some tea pots. When guides and tourists go to the tea rooms of different nationalities, they can combine some tea pots on the road to explain the relevant tea customs to tourists, and help visitors to further understand the tea culture in Xinjiang. For example, when tourists travel in Kazakh settlements, in the Kazakh tea-dwelling houses, the Kazakhs must use boiled tea, clean tea sets, and crack-free and cracked tea bowls to showcase the Kazakh custom that every party has tea. Another example is the drinking of tea houses in the Uyghurs, so that visitors can understand the customs of the Uyghurs.

\subsection{Multi-angle Development of Tea Culture Products}

Along with people's love for tea, many tea culture products have been derived, such as tea type, tea set, tea place, tea show and so on. Due to the diversity of its ethnic groups, Xinjiang has a unique tea set and distinctive national characteristics. Such as Kazakh embroidered tea bags and insulation mats, wooden carved tea trays and tea bowls and other tea sets; such as Uyghur tea, grape tea, cream tea, nut tea, egg tea, herbal tea, sweet tea and other tea. Lead tourists or tea culture researchers to go to the famous tea drinking places to enjoy tea, or go to the local tea shop market, and experience the local tea culture while introducing the tea and tea sets they are interested in. In addition to tea, tourism companies can also attach importance to and develop Xinjiang tea culture related products, which is beneficial to better promote Xinjiang tea culture.

\subsection{Creation of a New Model of Tea Garden Tourism}

Although Xinjiang is not the main tea-producing area in China, there are also some distinctive tea areas in Xinjiang, such as lavender tea in Ili, chamomile tea, apocynum venetum in Lop Nor, and Kunlun chrysanthemum under Kunlun Mountain. Based on different tea harvesting seasons, different boutique tea garden tourism routes and projects can be designed to allow visitors to participate in the process of tea picking, tea making, etc., and photography bases, health care, tea experience, home stays, cultural festivals, restaurants and composite tourism models in the tea garden can be designed to invite local tea culture researchers to interact with tourists in the form of lectures to provide visitors with new travel experiences.

\section{Conclusion}

China is not only the production place of tea, but also the birthplace of tea culture. Tea ceremony and tea science are subtle and profound. The diverse tea culture in Xinjiang has enriched China's tea culture, and the "Belt and Road" has created opportunities for Xinjiang tea culture to go global. With the help of tea culture fairs, tourism and online media, Xinjiang can seize the opportunity of "Belt and Road" to promote Xinjiang tea culture and better disseminate China's excellent tea culture. 


\section{Acknowledgement}

This work was supported by the a staged Achievement of Southwestern University for Nationalities, 2018 Ph.D. Innovative Research Project "Uygur Literature in the Eyes of Western Scholars in the Early 20th Century: A Case Study of Uygur Folk Literature in Gunnar Jalan of Sweden" (Project No. CX2018BS21).

\section{References}

[1] Dai Youshan. Cultural Warfare, Beijing: Intellectual Property Publishing House. 2014:55

[2] Sun Zhihui. Food Health Fast Book on "Compendium of Materia Medica", Tianjin: Tianjin Science and Technology Press, 2014: 502.

[3] Tang Libiao. Xinjiang Tea Customs, Tea Communication, 2004: 38.

[4] Tang Libiao. Xinjiang Tea Customs, Tea Communication, 2004:39.

[5] 2018 China (Urumqi) International Tea Industry Expo and Purple Clay, Ceramics, Tea Sets Exhibition, Mainly grown in Ili and Usu.

[6] Abdullah: A hand-washing pot, made of copper, bronze or aluminum by the craftsman, now usually made of copper and plastic.

[7] Samarwal: A round water-burner made of copper or iron.

[8] Tinus: A tray or tea tray used for serving tea by Uighur.

[9] Piale: A small tea bowl specialized for tea drinking by Uighur. 